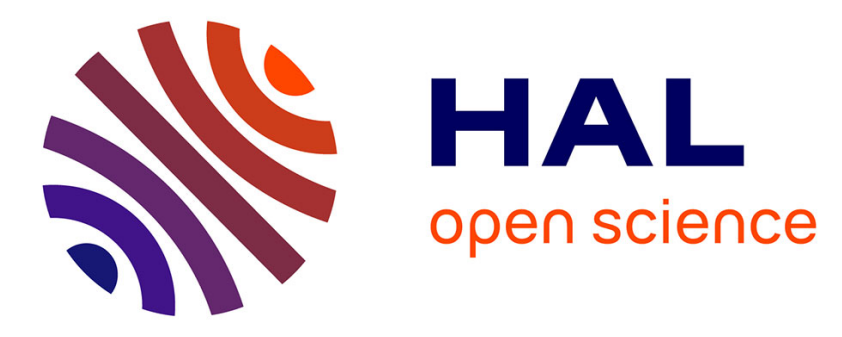

\title{
Monitoring of railway structures of the high speed line BPL with bituminous and granular sublayers
}

Diana Khairallah, Juliette Blanc, Louis Marie Cottineau, Pierre Hornych, Jean Michel Piau, Simon Pouget, Mohsen Hosseingholian, Alain Ducreau, Fréderic Savin

\section{To cite this version:}

Diana Khairallah, Juliette Blanc, Louis Marie Cottineau, Pierre Hornych, Jean Michel Piau, et al.. Monitoring of railway structures of the high speed line BPL with bituminous and granular sublayers. Construction and Building Materials, 2019, 211, pp.337-348. 10.1016/j.conbuildmat.2019.03.084 . hal-03105719

\section{HAL Id: hal-03105719 https://hal.science/hal-03105719}

Submitted on 18 Jan 2021

HAL is a multi-disciplinary open access archive for the deposit and dissemination of scientific research documents, whether they are published or not. The documents may come from teaching and research institutions in France or abroad, or from public or private research centers.
L'archive ouverte pluridisciplinaire $\mathbf{H A L}$, est destinée au dépôt et à la diffusion de documents scientifiques de niveau recherche, publiés ou non, émanant des établissements d'enseignement et de recherche français ou étrangers, des laboratoires publics ou privés. 


\title{
Monitoring of railway structures of the high speed line BPL with bituminous and granular sublayers
}

\author{
Diana Khairallah', Juliette Blanc ${ }^{2}$, Louis Marie Cottineau², Pierre Hornych², Jean- \\ Michel Piau', Simon Pouget ${ }^{3}$, Mohsen Hosseingholian ${ }^{1}$, Alain Ducreau ${ }^{4}$, Fréderic Savin ${ }^{5}$ \\ ( ${ }^{1}$ Railenium, Valenciennes, France, diana.khairallah@railenium.eu) \\ ( ${ }^{2}$ IFSTTAR, Bouguenais, France, juliette.blanc@ifsttar.fr) \\ ( ${ }^{3}$ EIFFAGE, Corbas, France, simon.pouget@eiffage.com) \\ ( ${ }^{4}$ SNCF Réseau, Nantes, France, alain.ducreau@reseau.sncf.fr) \\ $\left({ }^{5}\right.$ SETEC, Paris, France, frederic.savin@ferro.setec.fr) \\ Corresponding Author: Diana Khairallah, Ph.D. \\ Corresponding Author's Institution: Railenium \\ First Author: Diana Khairallah, Ph.D. \\ Keywords: Ballasted railways, monitoring, asphalt concrete, bituminous \\ underlayment, granular sublayer, sensors, data acquisition
}

\begin{abstract}
Ballast deterioration, under dynamic loads, remains an important issue on high-speed tracks that can lead to high maintenance costs. This ballast deterioration leads to settlements. Several studies have shown that these settlements were linked to high accelerations produced in the ballast by high-speed train (HST) passages. The solution with bituminous underlayment was used since 1980s in several countries like United States, Italy, Spain, especially on high-traffic and high-speed lines (HSL). In France, the interest in this technique is recent. Following the East European HSL satisfactory behavior, a layer of asphalt concrete was used under the ballast layer of the Bretagne-Pays de la Loire (BPL) HSL. It is intended, in addition to the schedule savings and the protection of the subgrade during the construction phase, to reduce acceleration amplitudes produced at the passage of HST, to ensure moisture stability in the subgrade and thereby to decrease the maintenance costs of the tracks.
\end{abstract}

BPL HSL includes $105 \mathrm{~km}$ of innovative track with an asphalt concrete (GB) ballast sublayer, and $77 \mathrm{~km}$ with a granular layer under the ballast (UGM). Out of the instrumented sections of the BPL track, 3 sections are constructed with GB subballast layer and one with a layer of UGM as a subballast layer. A total of 127 sensors that includes accelerometers, anchored displacement sensors, temperature and humidity probes, and extensometers are used. Sensors are placed at various positions and depths in the track structures. Data were first acquired during a speed up test phase, under controlled conditions, with the same train passing at speeds ranging from 160 to $352 \mathrm{~km} / \mathrm{h}$. This paper presents the different sensors used for the instrumentation as well as the acquisition system installed to collect all measurements. Data treatment and processing is explained in details. Finally, results obtained for different speeds are presented, with a focus on accelerometer and anchored displacement sensor measurements, on two sections, allowing, among others, comparisons between the response of structures with and without asphalt concrete. The role of the GB, as a subballast layer, in damping the vertical displacement of the sub ballast structure and reducing the accelerations peaks in the ballast layer for ballasted tracks is demonstrated.

\section{Introduction}


Despite the severity of the criteria for ensuring the quality of ballast, the condition of tracks never reaches absolute perfection. There are still irregularities that affect the stability of the track. The main causes of track degradation are ballast settlement and evolution of the dynamic stresses on the railway track. Ballast deterioration, under dynamic loads, remains an important issue on high-speed tracks that can lead to high maintenance costs. Several studies have shown that these settlements are related to the high accelerations produced in the ballast by high-speed trains (Pita et al., 2004; Quezada, 2012; Saussine, 2004; Suiker, 2002).

The platform and the ballast layer may contain imperfections that damage the line (Guerin, 1996). Poor quality underlayment or poor drainage induces poor stress distribution between the ballast and the sublayer. If the ballast punches the sublayer, the fine particles move up into the ballast, affecting the drainage and the stiffness of the track and accelerating settlements by dynamic overloads.

The use of asphalt ballast sublayers has been identified as a possible solution for improving track structures. By interposing a semi-rigid layer of asphalt concrete (GB) between the ballast and the UGM layer, the behavior of the overall structure is greatly improved. This applies to both high-speed passenger and freight lines.

Asphalt concrete layers improve both the stability and durability of the structure, which helps to reduce the need for maintenance. They present several advantages: They improve the stiffness of the platform supporting the ballast and limit the risks of settlement, they allow reducing the thickness of the structures, and they protect the subgrade from moisture infiltration and improve drainage. The asphalt layer also creates a stiff construction platform, facilitating the movement of construction equipment on site (Albalat et al., 2011; Policicchio, 2007; Rose et al., 2011; Teixeira et al., 2010; 2014).

The use of asphalt concrete (GB) in railway construction has emerged in different countries. Indeed, over the last decade $322 \mathrm{~km}$ of sub-ballast layers have been built for new projects in the Midwestern United States; mainly for heavy freight traffic (Rose and Souleyrette, 2015).

The first use of asphalt mixes in high-speed railway construction in Italy dates back to the 1970s on all sections of the Rome-Florence "Direttissima" line (Buonanno and Mele, 2000). Experience has shown that the presence of a GB ballast sublayer in the railway structure also reduces the vibrations transmitted by trains passing to the surrounding environment. Asphalt concrete acts as a damping material. The Spanish railways have decided to test the use of an asphalt sub-layer instead of a granular sub-layer in test sections on four sites (Rose et al., 2010; Teixeira et al., 2006, 2009). In Japan, asphalt concrete has been widely used in ballasted railway tracks for many years, on high-speed lines and regular lines (Rose et al., 2010). The first objective of their use was to provide a firm support for the ballast and to reduce the irregularities of the track.

In 2005, SNCF built a $3 \mathrm{Km}$ long test section in the East HSL (LGV Est), linking Paris to Strasbourg, with a GB sublayer. The objective of this test section was to determine if this new design could represent an acceptable alternative for future rail infrastructure projects (Info, 2005). LGV Est is part of the rail network linking France with Germany, Luxembourg and Switzerland. This HSL has been in service since 2007, with French and German rail traffic passing at a commercial speed of $320 \mathrm{~km} / \mathrm{h}$. SNCF carried out various tests over 4 years to evaluate the GB impact on maintenance and observe the behavior during climate variations. Different sensors have been installed in both the innovative and conventional sections to measure the temperature, pressure, acceleration, stresses and deformations of the asphalt layer.

The data retrieved from this first instrumented test indicated satisfactory performance of the experimental railway section (Cardona et al., 2016; Robinet and Cuccaroni, 2012). The presence of the 
asphalt sublayer has proven to reduce the aggressiveness of the loading applied by passing trains, leading to an increase of the structure durability.

The measurements indicated lower vertical acceleration peaks on the structure with GB than on the classic section. This proves the effect of the asphalt layer on the stability of the structure. These results are in agreement with the results of (Di Mino et al., 2012). In service since June 2007, the test area with GB has required little maintenance, compared to neighboring conventional track sections (Cardona et al., 2016).

The HSL Bretagne-Pays de la Loire (BPL) line (between Rennes and Le Mans, in the West of France) is the first large-scale application of asphalt concrete sublayer technique in France (next to the East European HSL in its second phase), with varying subgrade conditions, and using higher performance asphalt materials. Therefore, the project "Monitoring of HSL BPL" has been launched to instrument several sections of the new high-speed BPL line. Led by Railenium, this project is the fruit of a collaboration that also involves Eiffage Infrastructures, SNCF Réseau, SETEC, the University of Lille and IFSTTAR. IFSTTAR, which has a great experience in pavement instrumentation, has instrumented the four sections (Blanc et al., 2017; Duong et al., 2018). Data acquisition and analysis started at the end of 2016, when trains were first put into circulation (for a test phase). The line has officially initiated its operations in July 2017 with trains travelling at a speed of $320 \mathrm{Km} / \mathrm{h}$.

\section{Structure of HSL Bretagne-Pays de Loire}

HSL BPL consists of $105 \mathrm{~km}$ of innovative track with an asphalt concrete (GB) sublayer under the ballast on its east route, and $77 \mathrm{~km}$ with a granular underlayment on its west route. An asphalt concrete (GB) of class 4 (GB4), according to French standard NF EN 13-108-1, has been used for this project.

\begin{tabular}{|c|c|c|c|}
\hline $\begin{array}{l}\text { Void Content } \\
\text { P.C.G }\end{array}$ & $\begin{array}{c}\text { Water } \\
\text { Content }(\mathrm{r} / \mathrm{R})\end{array}$ & $\begin{array}{c}\text { Stiffness modulus } \\
\left(15^{\circ} \mathrm{C}-10 \mathrm{~Hz}\right)\end{array}$ & $\begin{array}{c}\text { Fatigue admissible } \\
\text { deformation (at } 1 \\
\text { million cycles) }\end{array}$ \\
\hline & $>0$ & $\geq 11000 \mathrm{MF}$ & $\geq 100.10$ \\
\hline
\end{tabular}

The unbound granular material (UGM) has a particle size $0 / 31.5 \mathrm{~mm}$, and is of type A. According to French specifications, type $(A)$ corresponds to a material produced in a single fraction, which compactness at the OPM (optimum water content) calculated from the dry density is equal to or greater than $80 \%$, and which maximum grain size $D$ is less than or equal to $31,5 \mathrm{~mm}$. The innovative track structure, shown in Figure 1, includes the upper part of the earthworks (PST), which is treated with lime and hydraulic binders. The PST is surmounted by $15 \mathrm{~cm}$ of Unbound Granular layer (UGM) and a $12 \mathrm{~cm}$ thick asphalt layer. The standard structure comprises a $37 \mathrm{~cm}$ thick granular sublayer in addition to a cement-treated subgrade layer. 


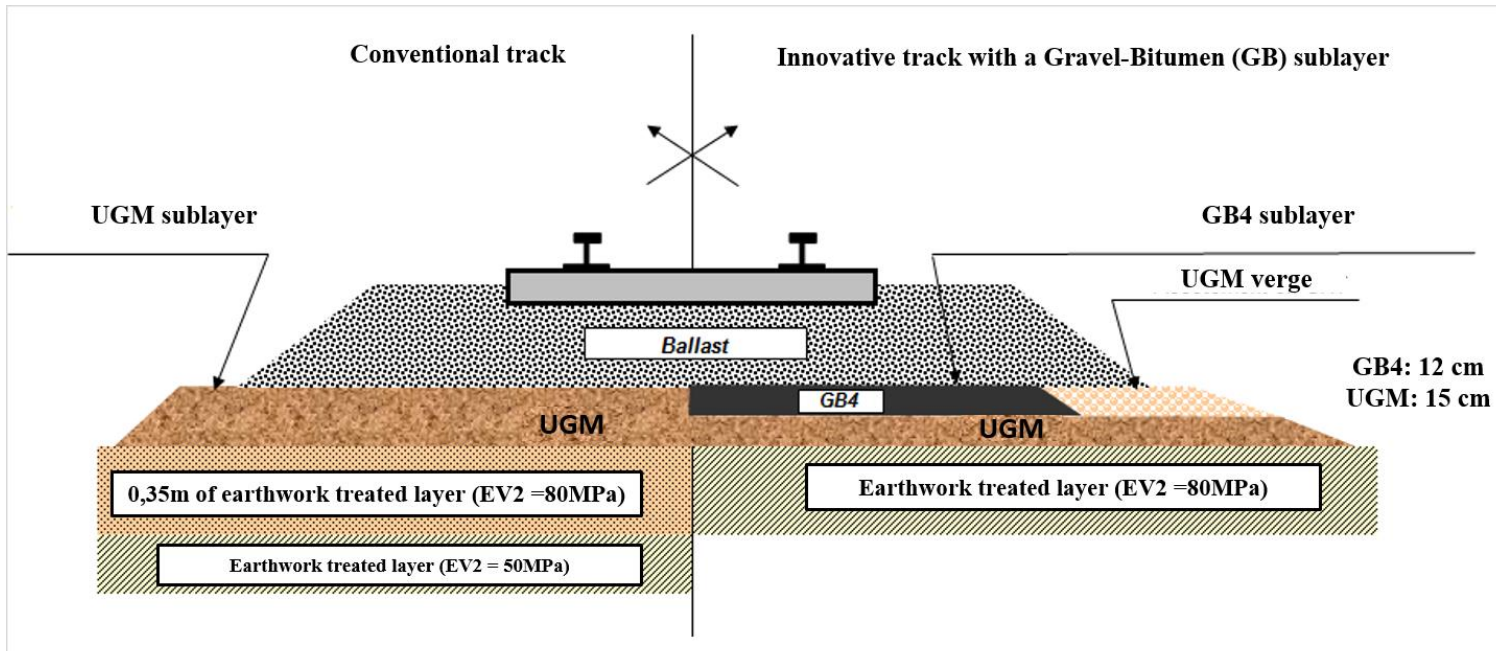

Figure 1 - Structure of the different sections with and without asphalt concrete. Figure translated

Four sections were instrumented (Figure 2): three sections with asphalt concrete underlayment and one with a standard granular structure (Khairallah et al., 2017). The objective of this instrumentation is to monitor the mechanical response of the different structures used on BPL HSL, by measuring accelerations, sub-ballast structure displacements, horizontal and vertical deformations and temperatures in different layers, and also water contents at the top of the subgrade. In this article, only acceleration and vertical displacement measurements of section 2 (with granular layer) and section 4 (with asphalt layer) will be presented and compared.

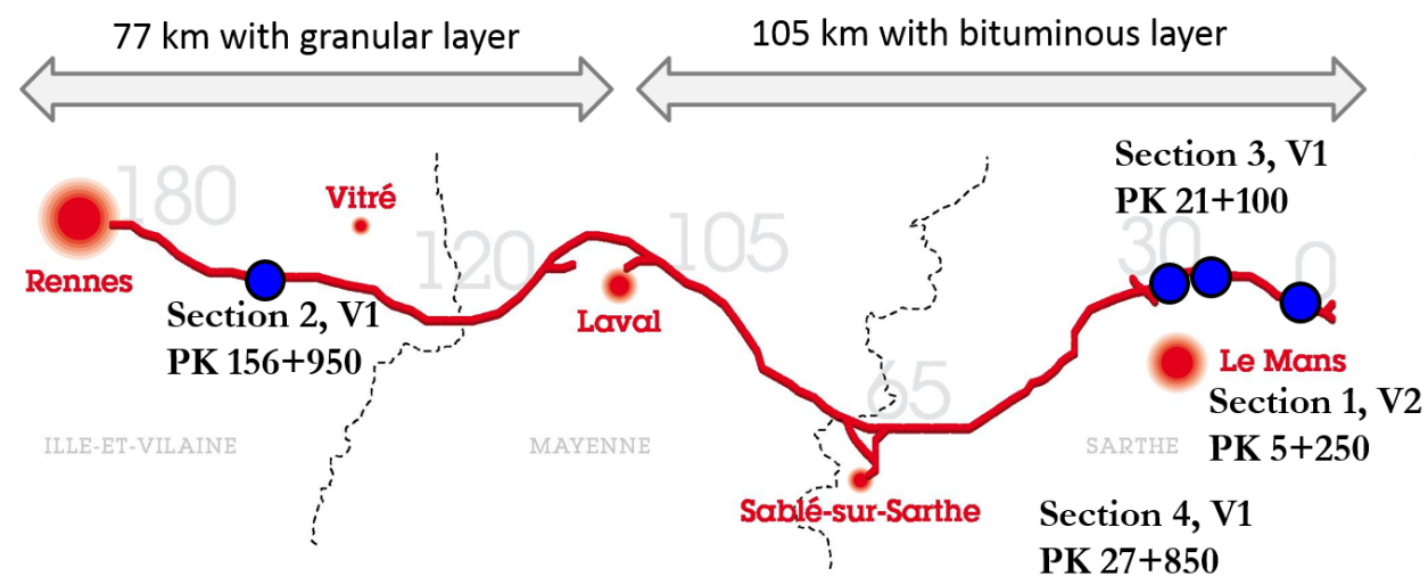

Figure 2 - HSL "Bretagne Pays de la Loire" lane

\section{Instrumentation: Sensors, Measurements and Acquisition system}

The objective of the instrumentation is to monitor dynamic responses of the different structures, and in particular to better understand the effects of the granular or asphalt sublayer on dynamic behavior and track durability. The following sensors (Figure 3), chosen and implemented by IFSTTAR, are used to monitor the different sections: 
- A weather station developed by A3IP to monitor environmental conditions (temperature and humidity, rainfall, direct sunlight, wind speed and orientation).

- Accelerometers (reference 2210-005 of Alliantech brand) to record the track's vertical dynamic behavior, with measurements at several levels: under the sleepers, at the top of the asphalt concrete layers and at the top of the granular layer. Acceleration measurements allow, in particular, comparing the sections' dynamic responses, with asphalt or granular sublayer.

- Strain gages (TML brand KM-100HAS) to measure longitudinal and transverse strains at the base of the GB layer, and temperature sensors (KIMO PT100 probes), placed at the top and bottom of the layer.

- Vertical strain gages (TML brand KM-100B) and TDR moisture content probes (CS650-DS), to quantify water content variations. These gages measure deformation levels of the unbound granular material (UGM). As a result, effects of seasonal moisture content variations can be inferred from the measured deformations.

- An anchored displacement sensor, measuring the total deflection between the top of the GB for section with asphalt sublayer and the top of the UGM for the section with granular sublayer, and a reference point located at $6 \mathrm{~m}$ depth. This sensor measures the structure's total displacement under the ballast (GB + granular layer + subgrade for section with bituminous sublayer or UGM + subgrade for section with granular sublayer).

(a)

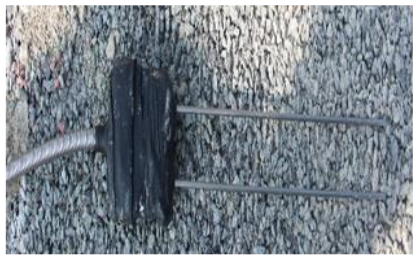

(e)

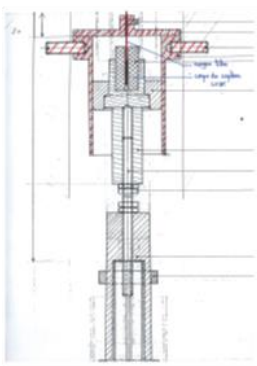

(b)

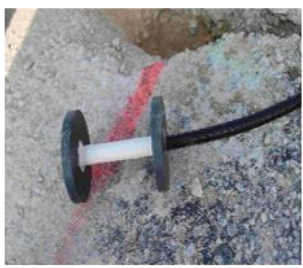

(c)

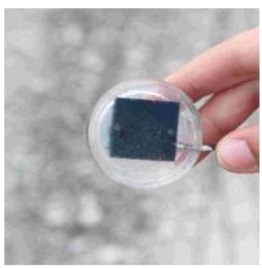

(g) (d)

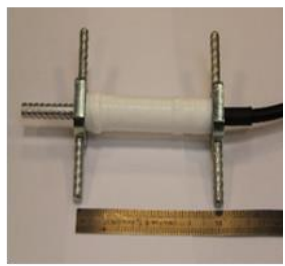

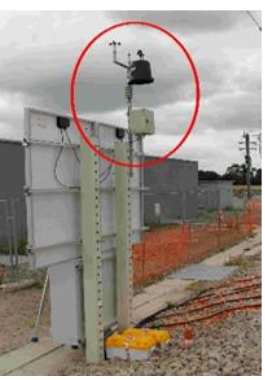

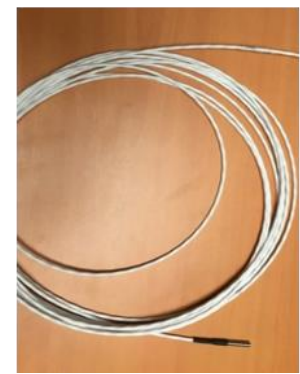

Figure 3 -Installed sensors to monitor the railway track: (a) humidity probe (b) vertical strain gage (c) accelerometer (d) horizontal strain gage (e) anchored displacement sensor (f) weather station ( $g$ ) temperature probe.

Locations of the four sections are indicated on Figure 1, and sections 2 and 4 are instrumented as follows:

- Section 2: Toarc A - PK $156+950 \mathrm{~m}$ V2 instrumented with 6 vertical strain gages in the UGM layer, 16 accelerometers, 4 moisture content probes in the UGM, 2 temperature sensors, 2 anchored displacement sensors and a weather station.

- Section 4: Toarc F - PK $27+850$ V2 instrumented with 6 vertical strain gages, 10 horizontal strain gages in the asphalt layer, 8 accelerometers, 4 moisture content probes, 3 temperature sensors, 2 anchored displacement sensors and a weather station. 
A scheme of the implementation of accelerometers and anchored displacement sensors for section 2 (granular sublayer) and section 4 (asphalt sublayer) is presented in Figure 4.

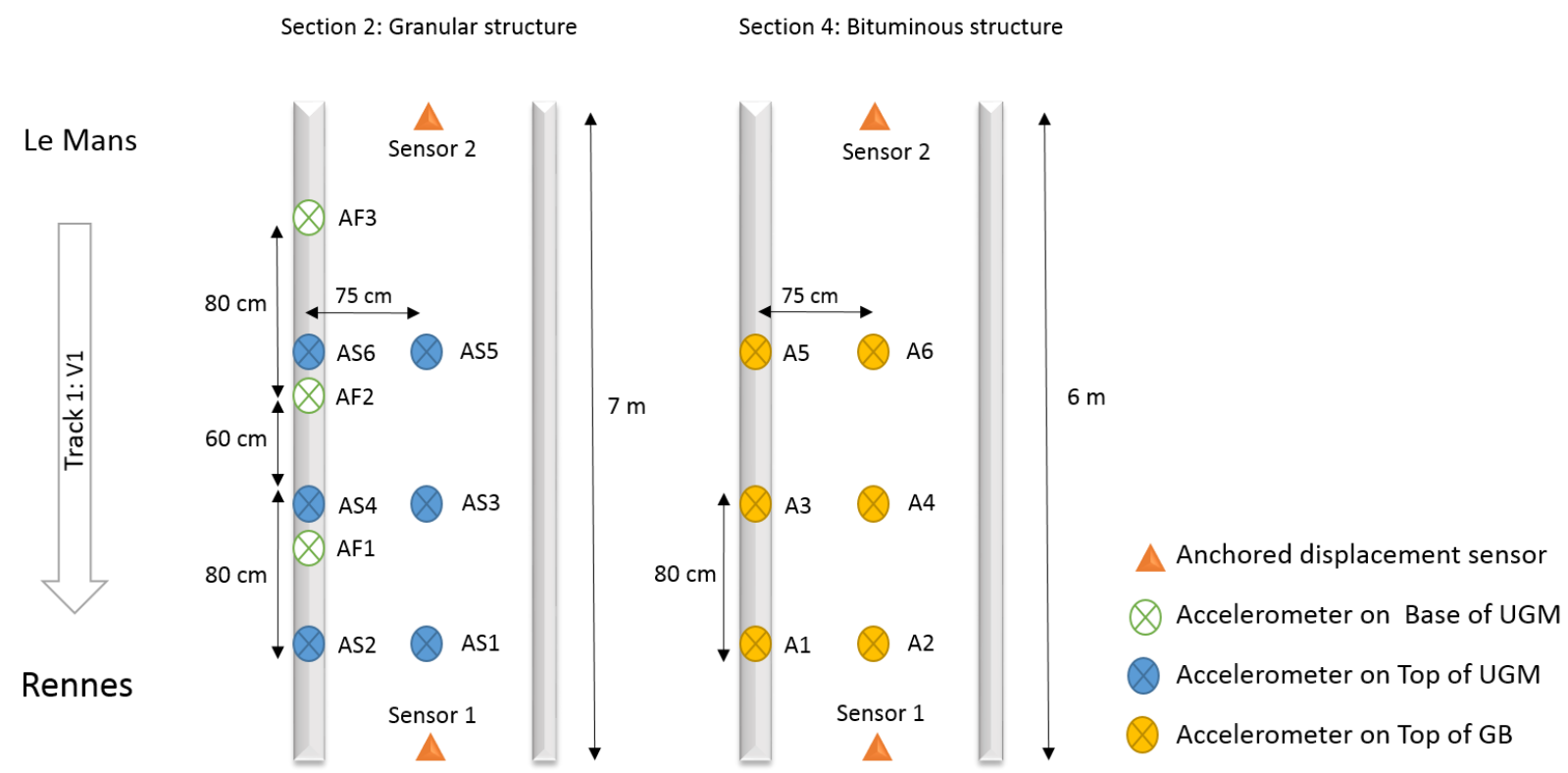

Figure 4-Sections 2 and 4 : instrumentation layout for accelerometers and displacement sensors

At each section's level, two types of measurements are performed : "slow" measurements and "fast" measurements. Slow measurements involve temperature probes, water content probes, weather data and anchored displacement sensors. These measurements are recorded continuously every 5 minutes. Fast measurements include accelerometers, vertical and horizontal extensometers and anchored displacement sensors. Fast measurements are recorded under the passage of trains. They are triggered when the measured acceleration exceeds a certain threshold (threshold set for an accelerometer placed at the top of the first sublayer). The threshold is fixed at a very low value in order to record all train passages. The signal acquisition frequency is $2000 \mathrm{~Hz}$ (Khairallah et al., 2017).

On each site, acquisition systems are installed in a weatherproof cabinet resistant to vibrations of trains with $320 \mathrm{~km} / \mathrm{h}$ velocity. Cabinets are powered by a built-in system (solar panels + batteries) for uninterrupted year-round operation. Based on their performance and previous experience, acquisition systems based on the PEGASE platform developed by IFSTTAR (Le Cam et al., 2010) and produced by A3IP were chosen. This platform is modular, to fit various needs without a long and costly development process (Le Cam et al., 2008). Generic Experts Platform for Embedded Wireless Applications (PEGASE) is a concept derived from intelligent and wireless instrumentation. This system has been designed to support the needs of instrumentation such as wireless communication, dating, and signal processing... Saved results on all sections are transferred continuously via 3G network (within few hours at most) to a remote server. Results are stored in a relational database, enabling fast-multi-criteria searches. A remote webserver authorizes the management of several instrumented sites along with their measurement systems, including the weather station. Acquisition parameters can be configured remotely, through a web application. For each acquisition board, the slow and fast measurements can be visualized in real time.

Data acquisition carried out on BPL HSL is divided in two phases. The first phase, entitled "speed up phase", corresponds to a test phase of the track, before the start of commercial traffic. The passing HST characteristics are known, with increasing speeds ranging from 160 to $352 \mathrm{~km} / \mathrm{h}$. The HST is 
composed of 13 bogies and weighs 380 tons. Bogie axle loads are summarized in Figure 5. Their wheelbase is $3 \mathrm{~m}$ long. The second acquisition phase corresponds to the commercial traffic phase; where the average train speed is $320 \mathrm{~km} / \mathrm{h}$, and where different high-speed trains, with different bogie loads and characteristics pass on the track. In this article, only results of the speed up test phase are detailed. Different comparisons are plotted and train speed influence on track response is analyzed, taking advantage of the fact that the same train, with the same loads, has been used during all this phase.

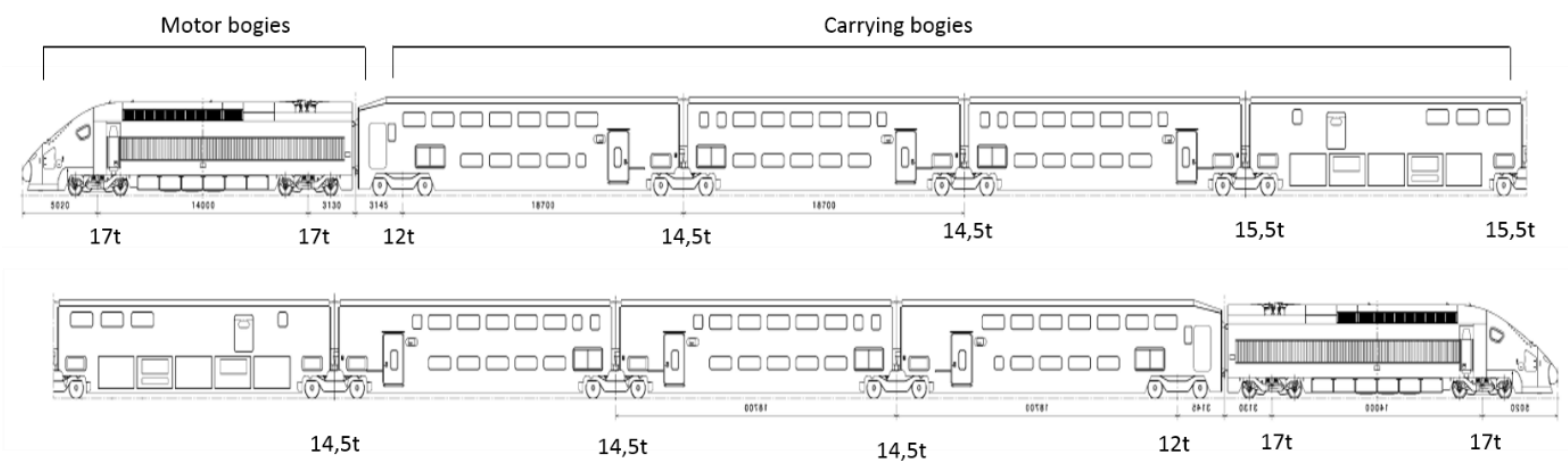

Figure 5 - High-Speed Train used in the Speed up test phase

\section{Data processing during speed-up test phase}

Before opening the BPL track to commercial traffic, a series of tests were performed on the track, at increasing speeds, between November 2016 and January 2017. These tests were performed with the same HST, with known loads, and train speeds varying from $160 \mathrm{Km} / \mathrm{h}$ to $352 \mathrm{Km} / \mathrm{h}$. Since the loads were always the same, responses obtained on different sections, and at different speeds, can be easily compared.

\section{General description}

A train journey on the BPL railway track generates more than 50 data files that need to be treated and plotted. Scilab, a free numerically oriented programming language is used to automate signal processing.

Different routines and functions have been developed, using Scilab, to complete the following steps, leading to visualization of signals:

- Scale the measurements of the various sensors installed.

- Calculate the speed of the passing HST train at this date.

- Filter the recorded sensor signals using a low pass filter.

- Select the desired sensor(s) to plot their signal(s).

- Visualize the needed time signals.

These steps have been programmed with Scilab for all the sections. The section(s) to study can be selected at the beginning of the data processing program. It is possible to run multiple calculation functions, read data files, scale, filter, calculate velocities, process and plot graphs.

\section{Calculation of train speed}


As previously mentioned, two anchored displacement sensors are installed on the section with asphalt sublayer (section 4), separated by a distance of $6 \mathrm{~m}$. On the section with granular sublayer (section 2 ), two sensors are also installed, $7 \mathrm{~m}$ distant.

Figure 7 presents typical vertical displacement signals measured on section 2, for a train speed of 160 $\mathrm{km} / \mathrm{h}$. The 13 bogies of the train can easily be identified visually. When the train passes, the time difference between the signals of the two displacement sensors can be used to calculate the train velocity, knowing the distance between the two sensors, as shown in Figure 6.

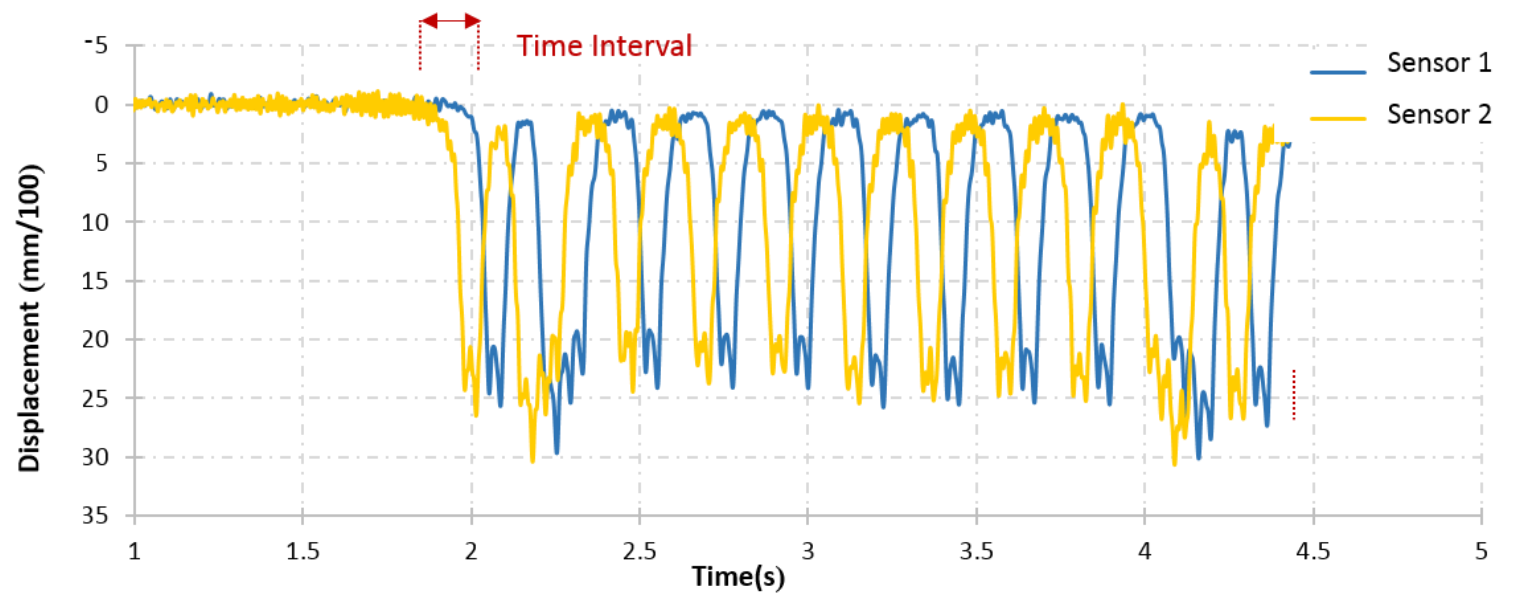

Figure 6 - Filtered signals of two anchored displacement sensors - Train speed $160 \mathrm{~km} / \mathrm{h}$

\section{Signal Filtering}

Once the train speed is calculated, the program filters the signals by a low-pass filter, adjusted according to train speed, to eliminate the high frequency components, due to dynamic effects. The cut off frequency is calculated by dividing the vehicle speed, increased by $10 \%$, by the distance of $3 \mathrm{~m}$ separating the wheels of successive axles. This filtering facilitates extraction of signal peaks, in particular the peaks of the displacement and acceleration signals, in order to identify motor and carrier bogies.

\section{Determination of average response under carrier bogies}

The test train is composed of 8 wagons, with 7 intermediate carrier bogies, with negligible load differences. To evaluate the response of the track to the train loads, it was decided to calculate the average signal, corresponding to these identical bogies. The procedure consists in separating the signals corresponding to each carrier bogie (excluding the motor bogies), and plotting them from the same time origin. For each sensor the mean curve and the curves corresponding to $+/$ - one standard deviation are calculated.

For each filtered accelerometer and anchored displacement sensor signal, this "averaging" method has been applied to the seven carrier bogies constituting the high-speed train. 


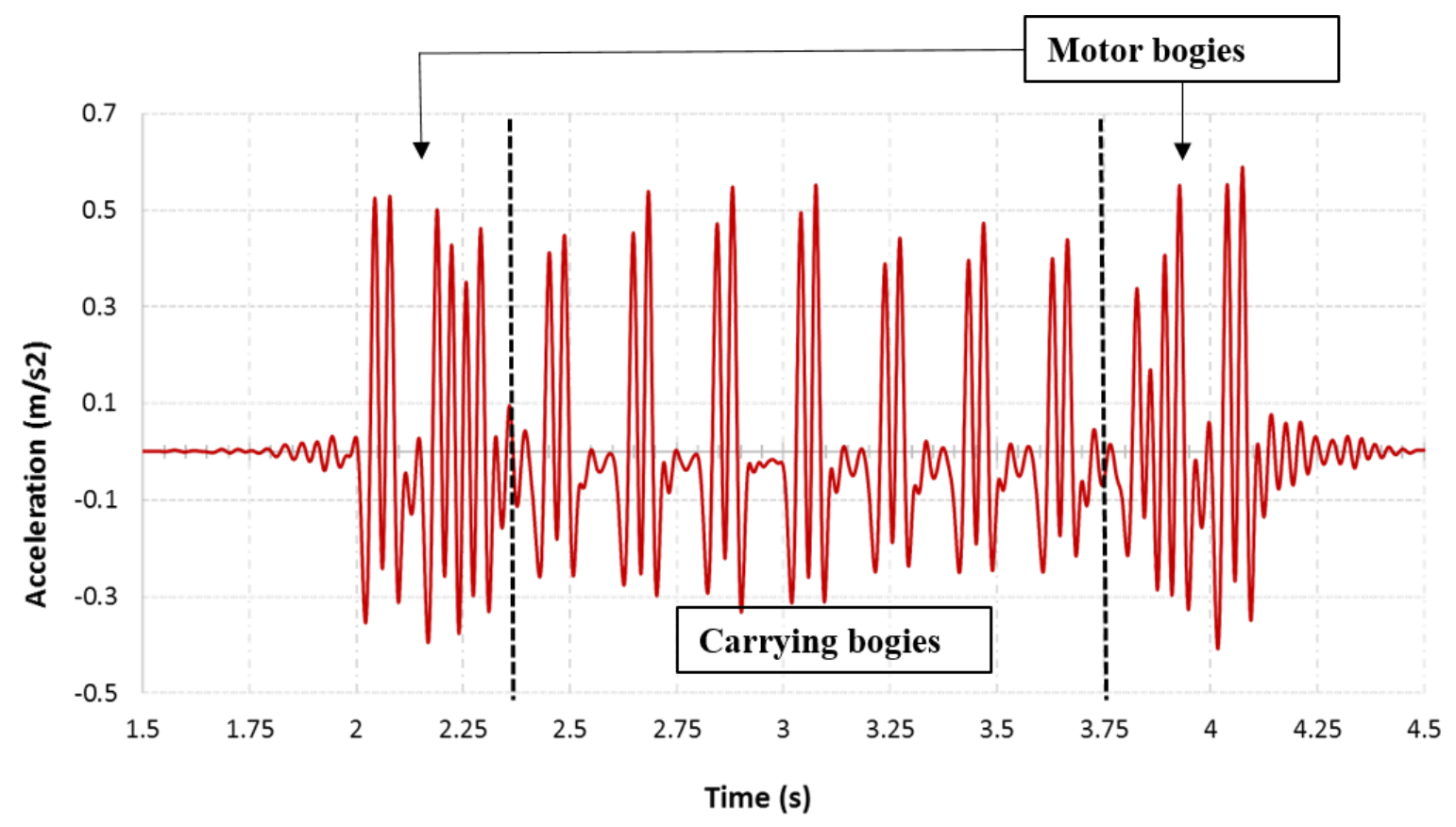

Figure 7 - Filtered acceleration signal for a train passage - Train speed $320 \mathrm{~km} / \mathrm{h}$ translated

In Figure 7, the filtered signal of an accelerometer is cut to isolate sequences related to the passage of the seven carrier bogies. To identify automatically each bogie, the procedure consists in subjecting the deflection signal to a low pass filter to eliminate the peaks above $10 \mathrm{~mm} / 100$. The time interval corresponding to each bogie signal is determined by calculating the number of points removed referring to the erased peaks. This interval is widened a little, to ensure that no part of the bogie signal is missed. Once the time interval corresponding to each bogie is determined, the signals corresponding to the seven carrier bogies can be extracted and superimposed.

Acceleration (as in Figure 8) and displacement (as in Figure 9) signals corresponding to the 7 carrier bogies of the train have been superimposed on the same graph, and represented as a function of distance (converting the time to distance, using the train velocity). The "average response" of the considered sensor has then been calculated point by point. The sign convention defines the positive values as upward accelerations and the negative ones as downward accelerations.

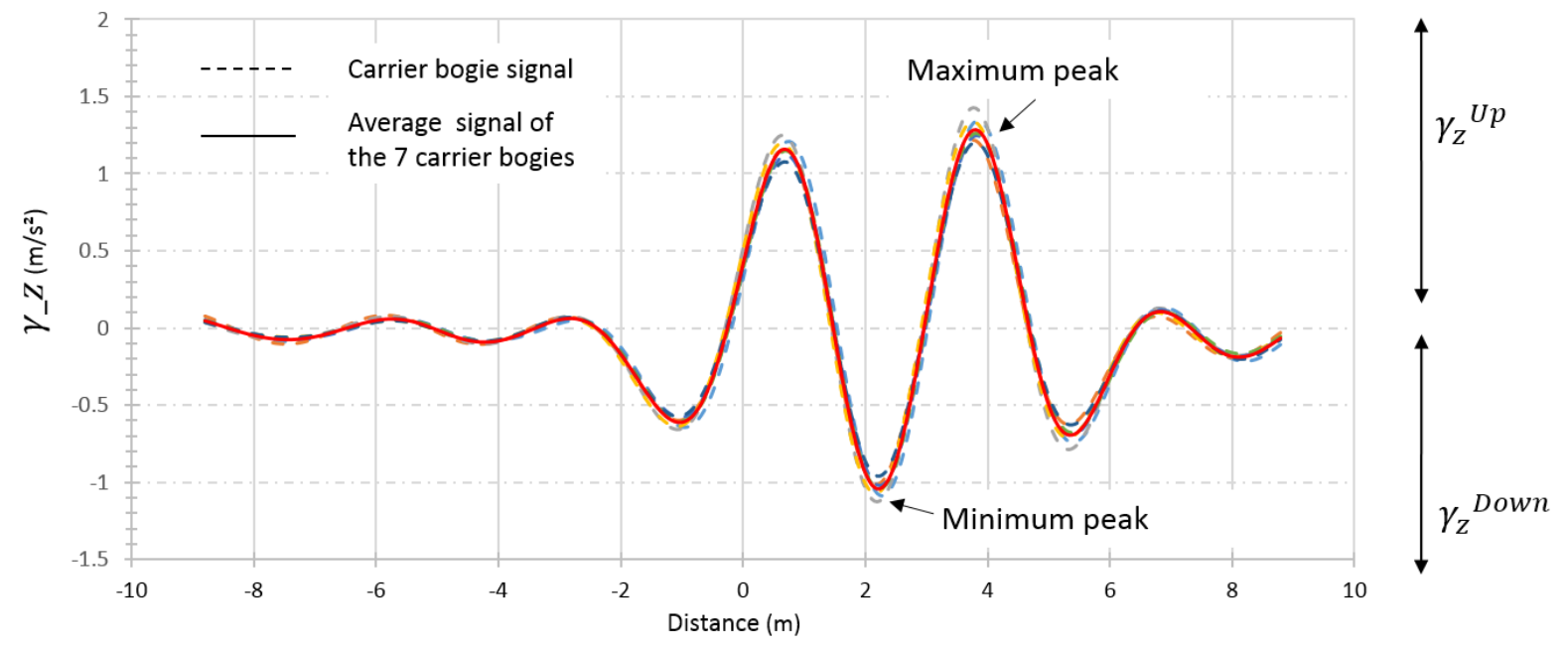

Figure 8-Superimposed acceleration signals of the seven carrier bogies, and average signal. 


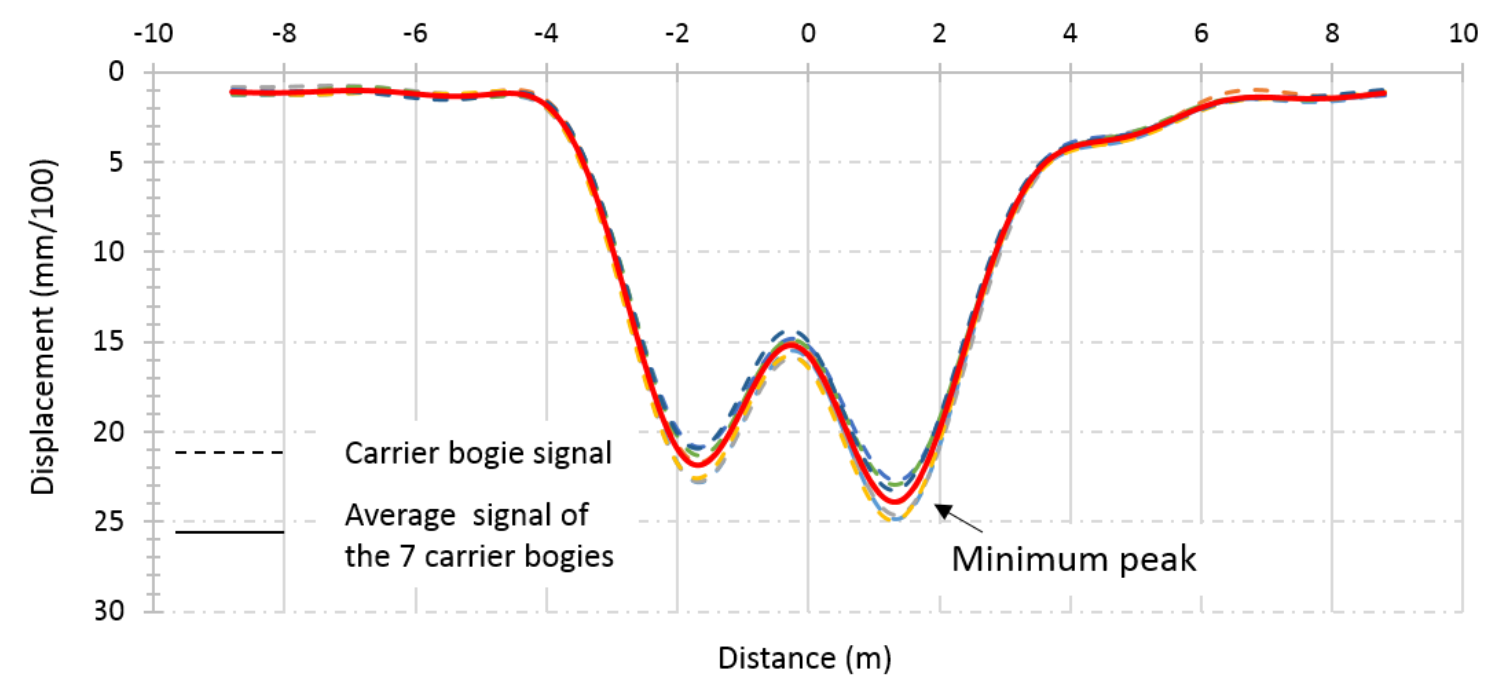

Figure 9-Superimposed displacement signals of the seven carrier bogies and average displacement signal

To verify the accuracy of the measurements, which is an essential point, a double derivation of the average displacement signals obtained on sections 2 and 4 has been performed, to obtain acceleration values. Derivative acceleration values have been compared with the direct measurements given by the accelerometers. The results of these comparisons are presented in Figure 10 for the UGM structure and in Figure 11 for the structure with the GB sublayer. It can be noted that the shapes of the curves, and the maximum amplitudes are very similar, confirming that the two types of measurements are consistent. This good match between the acceleration and displacement measurements is obtained both at low train speed $(V=160 \mathrm{Km} / \mathrm{h}$, Figure 10$)$ and at high train speed $(\mathrm{V}=320 \mathrm{Km} / \mathrm{h}$, Figure 11).

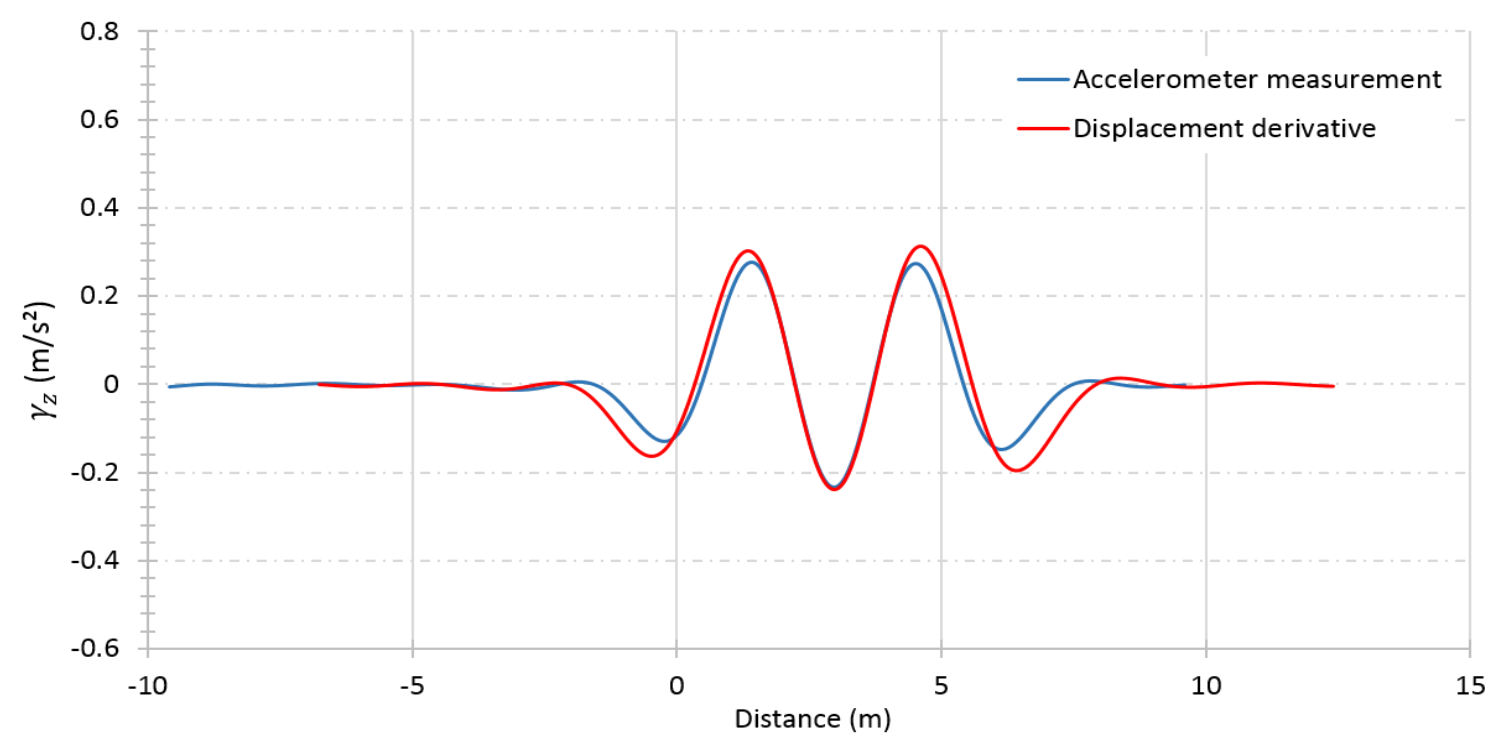

Figure 10-Average acceleration curves obtained from an accelerometer on section 2 (with granular sublayer) and from a derivative of the displacement curve - Train speed $160 \mathrm{~km} / \mathrm{h}$ 


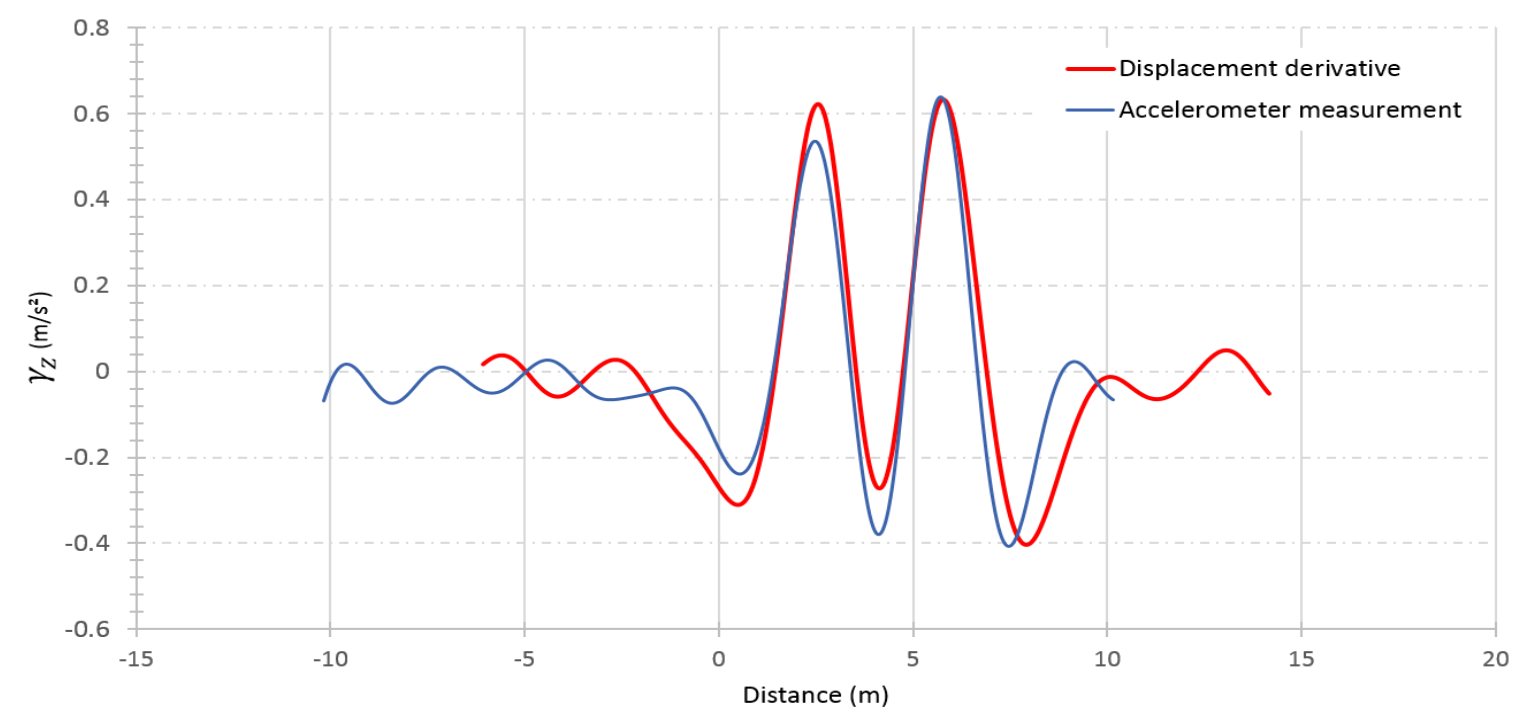

Figure 11 - Average acceleration curves obtained from an accelerometer on section 4 (with bituminous sublayer) and from a derivative of the displacement curve - Train speed $320 \mathrm{~km} / \mathrm{h}$.

\section{Comparison of the response of the structures with granular and asphalt sublayers}

One of the objectives of the project on "Monitoring of the BPL High Speed Line" is to evaluate the behavior of the structures with asphalt sublayers, and to compare it with traditional structures with granular sublayers. To achieve this objective, the measurements of the anchored displacement sensors installed in pairs on the asphalt and granular sections will first be compared. Then, the acceleration levels will be analyzed, in particular those obtained under the sleepers and the base of the ballast layer, which strongly influence the wear and settlements of the ballast layer(Chupin and Piau, 2011a; Chupin et al., 2014; Martin, 2014).

Since the behavior of bituminous materials is strongly dependent on temperature, it is important to note that during the three months of the speed up test phase (between November 2016 and January 2017), only small temperature variations were observed. Temperatures at the top of GB and UGM layer reached at maximum $10^{\circ} \mathrm{C}$ degrees in November and at minimum $2^{\circ} \mathrm{C}$ degrees during the coldest days in January. Therefore, temperature variations were neglected in the analysis of the results.

To compare the response of the two sections, the average signals obtained with the Scilab "averaging" procedure, explained above, will be analyzed. More precisely, the "maximum" positive accelerations (oriented downwards) and "minimum" negative accelerations (oriented upwards) will be compared. For the displacements, the maximum deflections of the track (oriented downwards) will be compared. These values and the standard deviation are determined from the mean signals of the seven bogies, to reduce variability.

The objective is in particular to compare the maximum downward vertical accelerations generated by the passage of the trains, which have the most damaging effect for the ballast layer, as they reduce the apparent weight of the ballast grains and the inter-granular friction forces (Chupin and Piau, 2011b). 
Figure 12 shows the maximum vertical deflection values measured on sections 2 (granular sublayer) and 4 (bituminous sublayer) as a function of train speed, during the speed up test phase. The displacements obtained on the two sections are very close, and of the order of $25 \mathrm{~mm} / 100$. These low and stable deflections are due to the high bearing capacity of the subgrade, which consists of cement treated soil on all the instrumented sections of the BPL line. Dynamic plate load test, performed every $20 \mathrm{~m}$ on the BPL track, have indicated that the bearing capacity of the subgrade exceeds $250 \mathrm{MPa}$, which is the highest value that can be measured with this equipment. The results also indicate no significant variation of deflections with speed. For the highest speed, reaching $352 \mathrm{Km} / \mathrm{h}$, maximum deflection values do not exceed $27 \mathrm{~mm} / 100$, on both sections. This means that results in terms of accelerations and strain amplitude could be directly compared in the analysis phase.

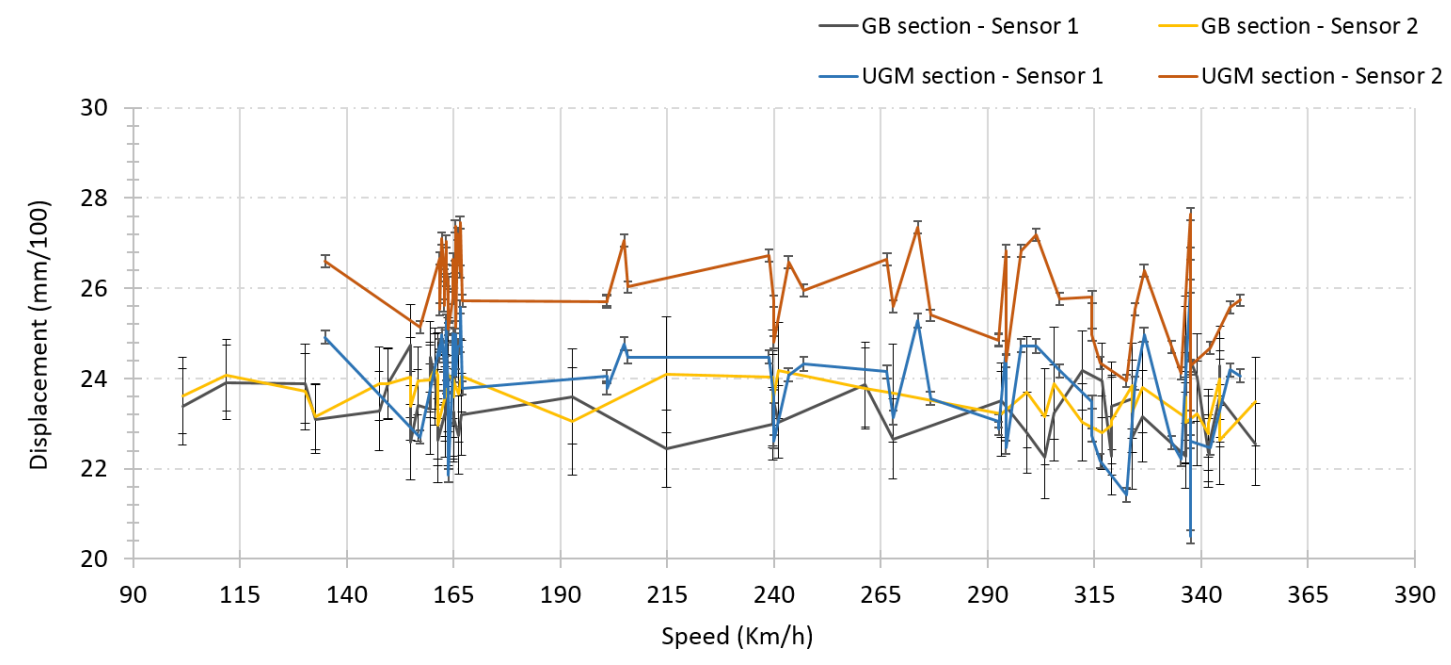

Figure 12 - Variation of vertical deflections, in function of train speed, for the sections with bituminous and granular sublayer.

Figure 13 presents a comparison between the average signals of the anchored displacement sensors on granular section 2 and asphalt section 4, for two trains passing at a speed of $320 \mathrm{Km} / \mathrm{h}$. It can be seen that the shape of the displacement signals is somewhat different on the asphalt section (blue and red curves), and on the granular section (gray and yellow curves). The displacements on the asphalt section are smoother, with only a small decrease between the two peaks, than on the granular section, where the drop between the two peaks is more important. The smoother signal obtained with the GB layer is probably due to the higher stiffness and higher damping properties of the GB layer, leading to a better spreading of the loads on the track 


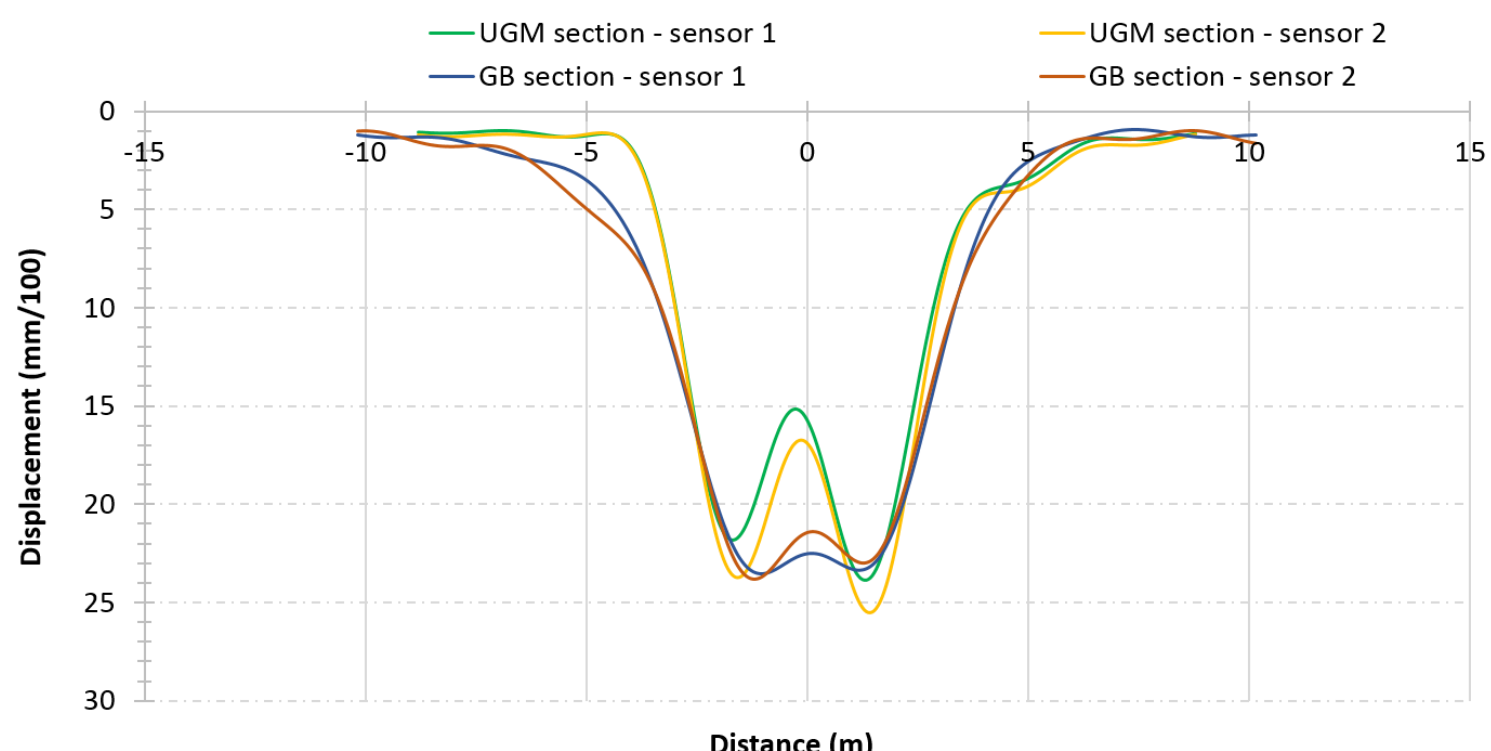

Figure 13 - Average signals of anchored displacement sensors on granular section 2 and bituminous section 4-Speed $320 \mathrm{~km} / \mathrm{h}$. color changed

The curves of Figure 13 also show that each pair of sensors gives very similar results, confirming the good accuracy of the displacement measurements.

Figure 14 compares the responses of the accelerometers installed at the top and at the base of the UGM layer on granular section 2, under the outer rail (see scheme on Figure 4). Figure 14 presents the maximum and minimum acceleration values, as a function of train speed. The dashed lines correspond to the accelerometers placed at the base of the layer, while the full lines correspond to those located at the top of the layer. The accelerations increase proportionally to the square of the train's speed, as expected when inertia forces are neglected, and are significantly higher at the top of the granular layer than at the bottom. At the top of the granular layer, the maximum accelerations vary between 1.3 and $1.7 \mathrm{~m} / \mathrm{s}^{2}$ at $340 \mathrm{~km} / \mathrm{h}$. Finally, the levels of the upward and downward accelerations are quite similar.

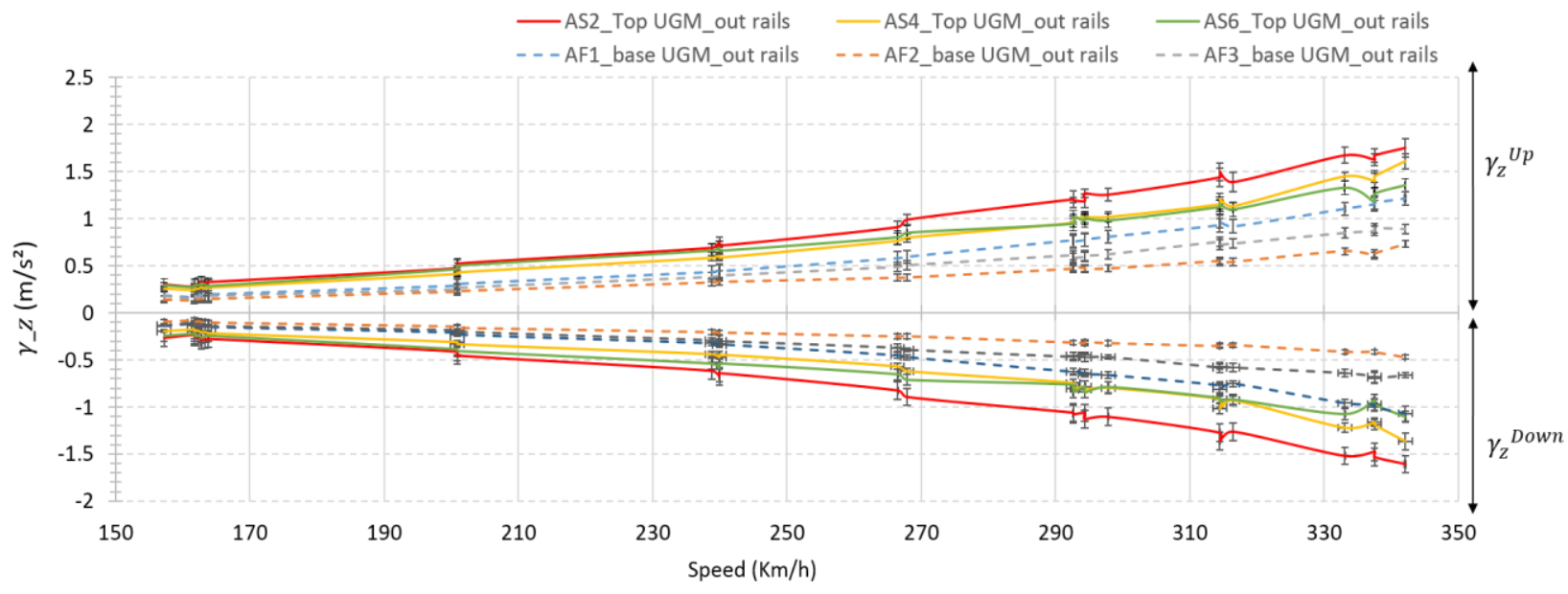

Figure 14 - Comparison between accelerometer results at top and base of the UGM layer.

Figure 15 presents maximum accelerations obtained on the innovative track structure with asphalt concrete sublayer, as a function of train speed. The sensors were installed at different positions, under 
the outer rail, and between the rails (see Figure 4). All the measurements show globally the same trend: accelerations present a non-linear increase with train speed. The highest maximum acceleration value attained in the section, registered with accelerometer $A 1$, is nearly $0.92 \mathrm{~m} / \mathrm{s}^{2}$, for a train speed of $352 \mathrm{Km} / \mathrm{h}$. This maximum acceleration is about two times lower than on the section with granular base. Thus, GB layers, as sub ballast layers, clearly lead to a reduction of accelerations levels in ballasted tracks.

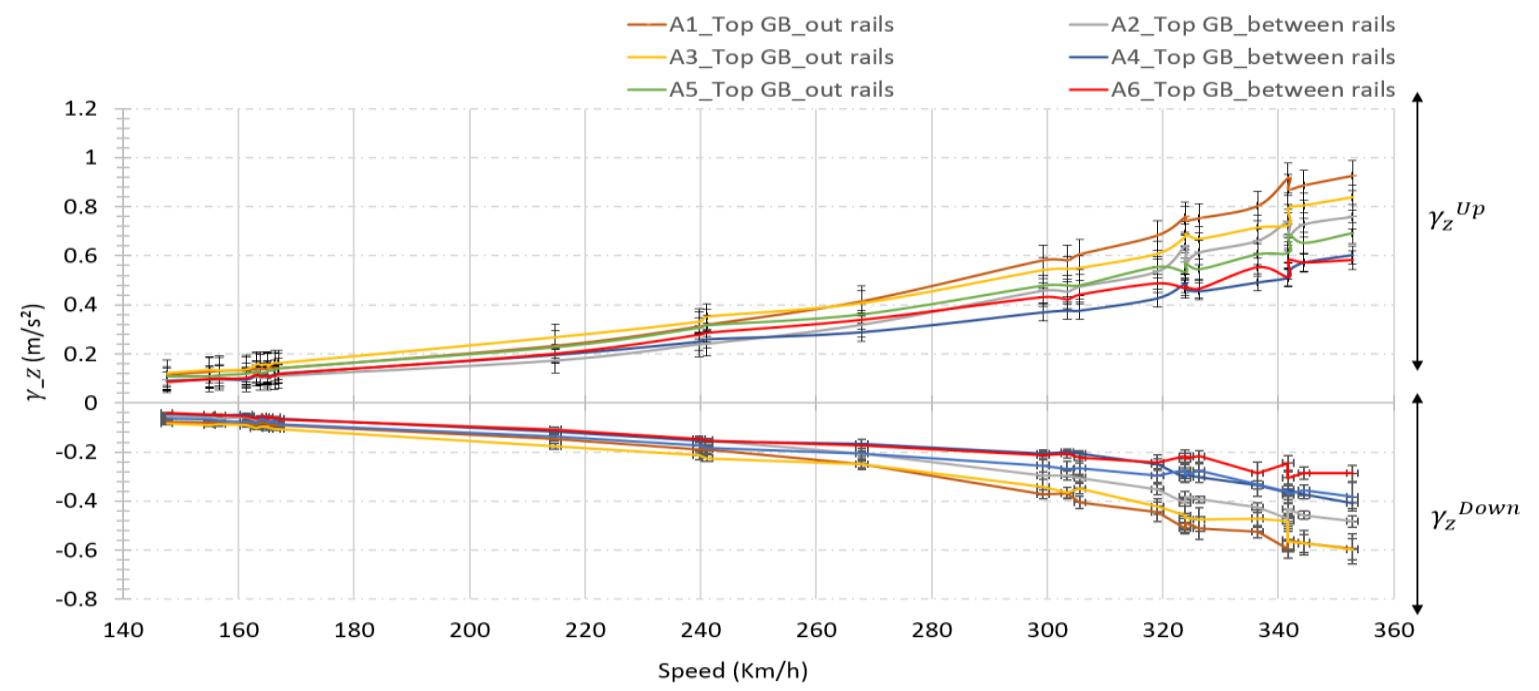

Figure 15 - Evolution of maximum accelerations in function of train speed, on the bituminous section 4

To compare the response of the two different structures, Figure 16 and Figure 17 present respectively the minimum and maximum accelerations (determined from the mean signal) for the accelerometers installed between rails (Figure 16) and under the outer rail (Figure 17).

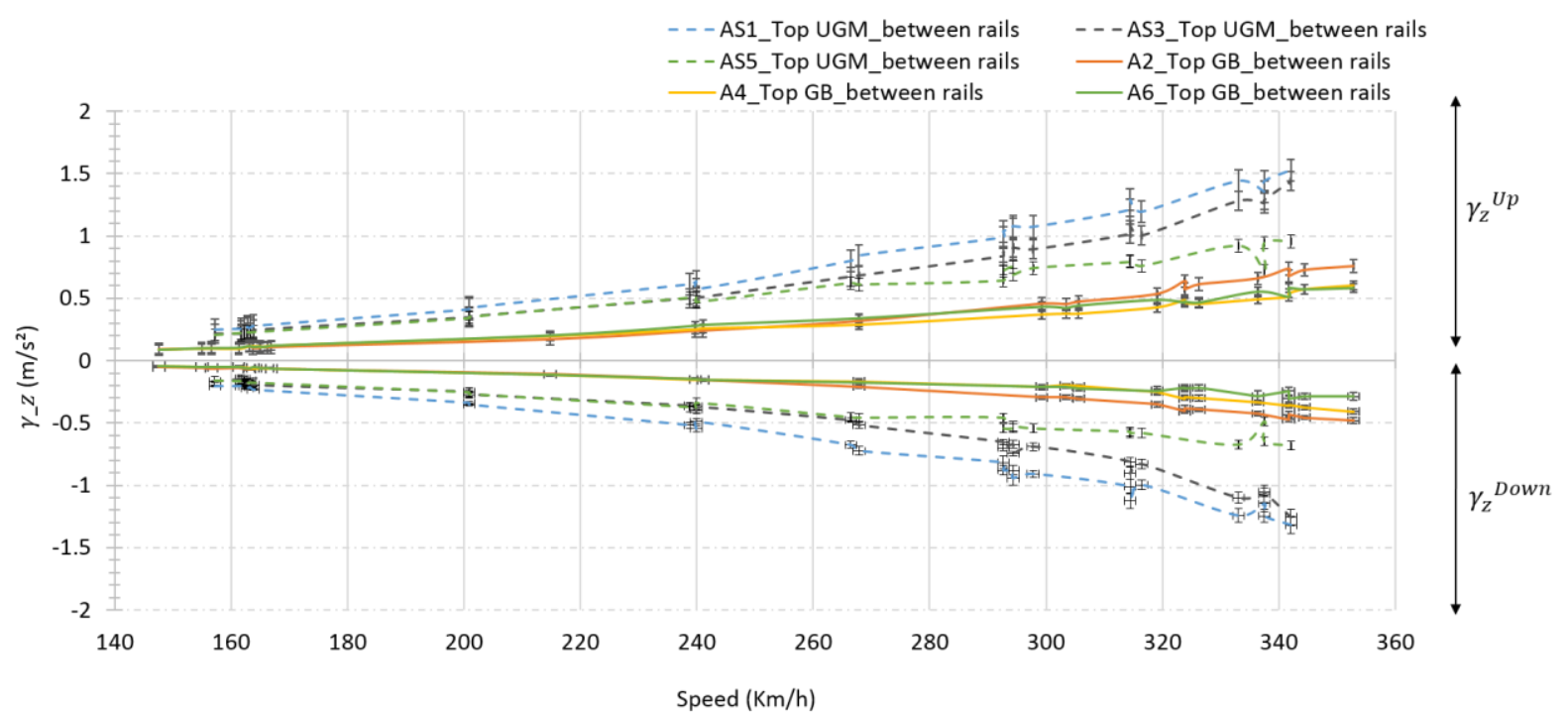

Figure 16 - Comparison of maximum accelerations on the granular and bituminous sections, for accelerometers installed between rails. 


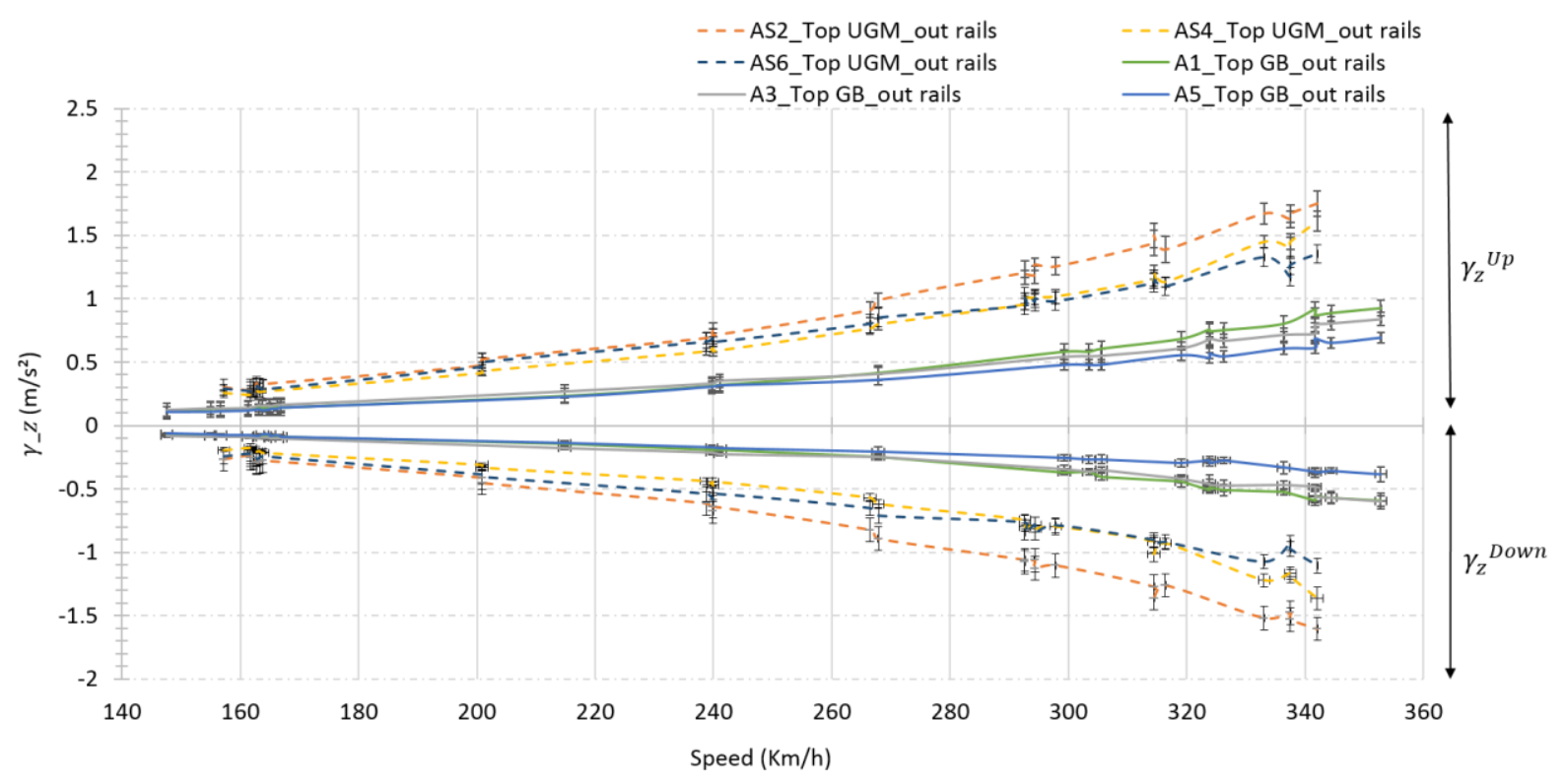

Figure 17 - Comparison of maximum accelerations on the granular and bituminous sections, for accelerometers installed under the outer rail.

The plot in the mentioned figures allows evaluating the behavior of the structures constructed with asphalt and granular underlayment and concluding on the influence of the asphalt concrete sublayer. The dashed lines represent the accelerometers of the granular section (2) and the full lines those of the asphalt section (4). For all the sensors, and for both upward and downward accelerations, the maximum accelerations at the top of the asphalt concrete sublayer are by far lower than those measured at the top of the granular sublayer. In other terms, from the different curves presented above, it can be concluded that the presence of the asphalt layer in the structure leads to a significant reduction (almost by a factor of two) of the accelerations under the ballast.

To evaluate the repeatability and reliability of the accelerometer measurements, Tables 2(a) and 2(b) summarize accelerations obtained for several different trains passing on the granular and asphalt structures at the same speed, close to $320 \mathrm{~km} / \mathrm{h}$, which corresponds to the commercial service speed on the BPL line. For all the sensors, the coefficients of variation of the accelerations vary between $2.1 \%$ and $7.6 \%$, despite the different sensor positions with respect to the rails, indicating a good performance of the different sensors. For a train speed of $320 \mathrm{Km} / \mathrm{h}$, the ratio between the accelerations recorded on top of the asphalt concrete and on top of the UGM layer can be estimated to $60 \%$. For the bituminous section, it can also be concluded that the accelerations between rails are lower than those measured under the outer rail. This result is logical, due to the fact that accelerometers under the outer rail are submitted directly to the train's loading. This reduction is not observed on the granular section. 
(a)

\begin{tabular}{cccccccc}
\hline & & \multicolumn{3}{c}{ Top UGM - out rails $\left(\mathrm{m} / \mathrm{s}^{2}\right)$} & \multicolumn{3}{c}{ Top UGM - between rails $\left(\mathrm{m} / \mathrm{s}^{2}\right)$} \\
Month & Speed $(\mathrm{Km} / \mathrm{h})$ & AS1 & AS3 & AS5 & AS2 & AS4 & AS6 \\
12 & 314 & 1.21 & 1.02 & 0.79 & 1.44 & 1.15 & 1.12 \\
1 & 314 & 1.29 & 1.08 & 0.80 & 1.50 & 1.21 & 1.15 \\
1 & 316 & 1.19 & 1.00 & 0.76 & 1.39 & 1.13 & 1.10 \\
Average & 315 & 1.23 & 1.03 & 0.78 & 1.44 & 1.17 & 1.13 \\
Standard Deviation(\%) & 0.36 & 4.18 & 3.98 & 2.72 & 3.81 & 3.52 & 2.42 \\
\hline
\end{tabular}

(b)

\begin{tabular}{cccccccc}
\hline & & \multicolumn{3}{c}{ Top GB - out rails $\left(\mathrm{m} / \mathrm{s}^{2}\right)$} & \multicolumn{3}{c}{ Top GB - between rails $\left(\mathrm{m} / \mathrm{s}^{2}\right)$} \\
Month & Speed $(\mathrm{Km} / \mathrm{h})$ & A1 & A3 & A5 & A2 & A4 & A6 \\
12 & 319 & 0.68 & 0.61 & 0.55 & 0.54 & 0.43 & 0.49 \\
1 & 324 & 0.76 & 0.68 & 0.53 & 0.64 & 0.49 & 0.47 \\
1 & 324 & 0.74 & 0.69 & 0.57 & 0.57 & 0.46 & 0.47 \\
1 & 326 & 0.75 & 0.67 & 0.54 & 0.61 & 0.46 & 0.47 \\
Average & 323 & 0.73 & 0.66 & 0.55 & 0.59 & 0.46 & 0.47 \\
Standard Deviation (\%) & 0.93 & 4.68 & 5.45 & 2.71 & 7.66 & 5.39 & 2.13 \\
\hline
\end{tabular}

Table 2 - Accelerations recorded on section with granular sublayer 2 (a) and with asphalt sublayer 4 (b) for several train passages, at an average speed of $320 \mathrm{Km} / \mathrm{h}$.

Figure 18 presents accelerations measured on the granular and asphalt sections, at the top of the sleepers. On the sleepers, the accelerations increase with speed, and present more scatter at high speeds (approximately above $300 \mathrm{~km} / \mathrm{h}$ ). This scatter of the track response at high speed can be due to a loss of stability of the ballast layer (settlements, or grain movements), when it is submitted to high frequency loading, and high accelerations (Martin, 2014).

There is also less influence of the asphalt concrete sublayer on the results. In average, on section 2 (granular sublayer) vertical accelerations are higher in magnitude than those of sensor "A7" installed on section 4 (asphalt sublayer). On this section, only one accelerometer has been installed on the sleeper. Despite the scattered results, a ratio of $50 \%$ between both sections can be observed. 


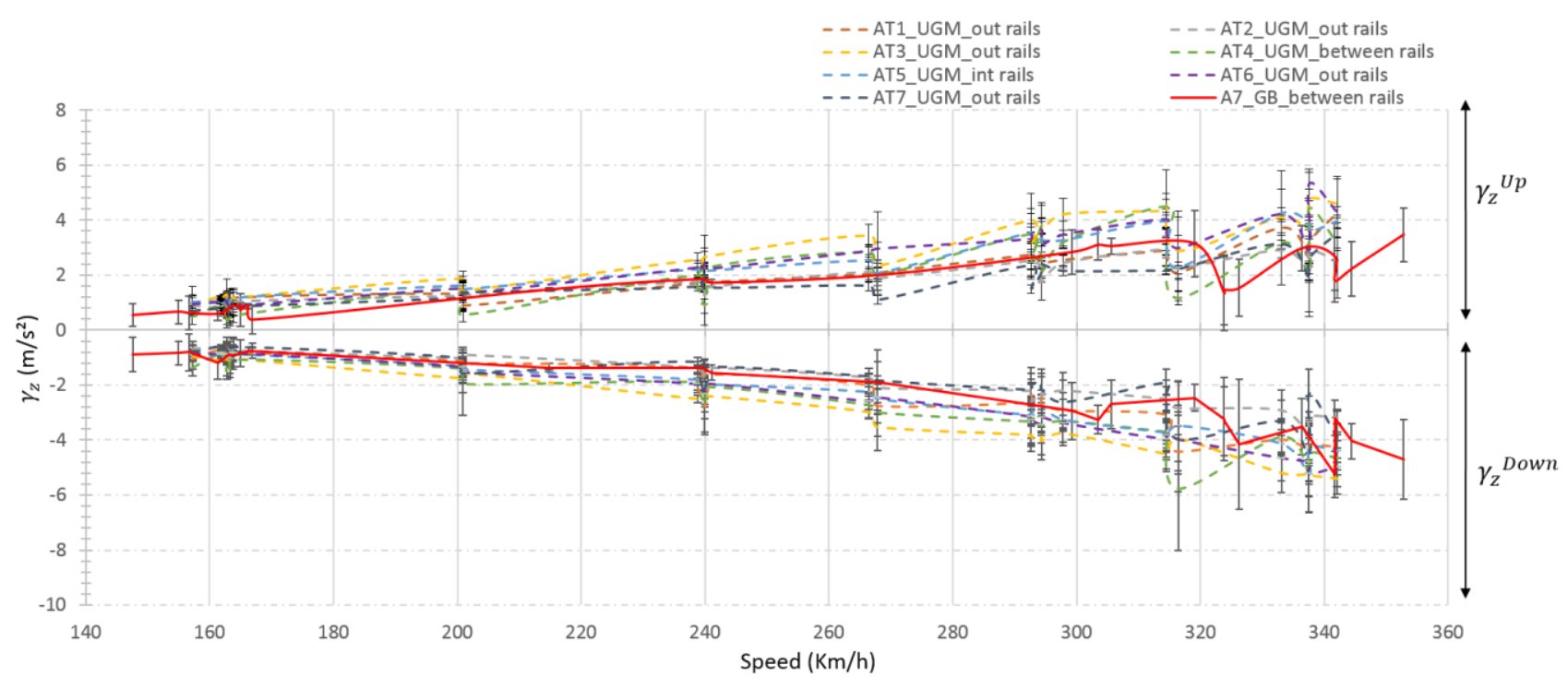

Figure 18-Comparison of maximum accelerations on the granular and bituminous section, for accelerometers installed on the top of the sleepers.

\section{Conclusion}

The phenomena of settlement and wear of the ballast on high-speed lanes, under dynamic stresses, lead to high frequencies of maintenance and high associated costs. One of the solutions proposed in the literature is to add an asphalt concrete layer under the ballast; it leads to an increase of the track stiffness, reducing the generated acceleration amplitudes. In order to study the influence of the asphalt sublayer, and the dynamic responses of the various railway structures with asphalt concrete and granular sublayer, four different sections of the "Bretagne - Pays de la Loire" high-speed lane have been instrumented using accelerometers, strain gages, displacement sensors, temperature sensors and moisture probes. Sensors are connected to fully autonomous acquisition systems, using solar panels and batteries for electric supply, and data transmission is done via 3G/4G network. The systems are fully remotely controllable.

Data acquisition has been successfully carried out during a speed-up test phase (with increasing train speeds up to $350 \mathrm{~km} / \mathrm{h}$ ). A data processing plan has been developed using Scilab routines. Programed routines can be used to filter sensor measurements, calculate train velocities, plot sensor outputs, superimpose signals of individual train bogies and determine curve peaks.

In this article, evolutions of track vertical accelerations and displacements, as a function of train speeds have been analyzed for two different instrumented track structures: a standard section with granular sublayer and an innovative section with asphalt concrete sublayer. Accelerations levels under the ballast induced by train passage increase when the velocity increases for both sections. The study has clearly demonstrated that the presence of the asphalt layer in the structure reduces the acceleration levels under the ballast that cause its deterioration, which is beneficial for the stability of the ballast layer. Deflection levels, on the other hand, are similar on both sections, but the asphalt concrete sublayer affects the shape of the deflection curves. More smooth deflection signals are obtained on the asphalt concrete sections, than on the granular sections, where deflections decrease rapidly between the two peaks corresponding to the two wheels of each bogie. The damping role of GB layers is highlighted. Reliability of the instrumentation outputs has been proved by evaluating the 
repeatability of accelerometer and displacement sensor measurements, and by comparing the accelerations derived from deflection curves with those recorded in place by the accelerometers.

Monitoring BPL line provides very complete data about the mechanical response of the track under high speed train loading. For the remainder of BPL track mechanical and dynamical behavior's study, strain gage measurements recorded during the speed up test phase, as well as track settlements, track layer temperature and water content variations during a whole year of functioning, will also be analyzed. Comparison of the experimental results with numerical modelling of the track response is also planned.

\section{Disclosure statement}

The authors reported no potential conflict of interest.

\section{Funding}

The authors would like to acknowledge the different partners of this project : Railenium, Eiffage, SNCF Réseau, Setec and the University of Lille.

\section{Bibliographic references}

Albalat, S.A., Domingo, L.M., Sanchis, I.V., Herráiz, J.I.R., and Segarra, A.V. (2011). Crumb Rubber Modified Bitumen for sub-ballast layer. $p$.

Blanc, J., Hornych, P., Duong, N.S., Blanchard, J.-Y., and Nicollet, P. (2017). Monitoring of an experimental motorway section. Road Mater. Pavement Des. 1-16.

Buonanno, A., and Mele, R. (2000). The use of bituminous mix sub-ballast in the Italian State Railways. pp. 20-22.

Cardona, D.R., Di Benedetto, H., Sauzeat, C., Calon, N., and Saussine, G. (2016). Use of a bituminous mixture layer in high-speed line trackbeds. Constr. Build. Mater. 125, 398-407.

Chupin, O., and Piau, J.-M. (2011a). Modeling of the dynamic response of ballast in high-speed train structures. p. pp-712.

Chupin, O., and Piau, J.-M. (2011b). Modélisation de la réponse dynamique d'une structure ferroviaire multicouche sous chargement roulant. p. 6 p.

Chupin, O., Martin, A., Piau, J.-M., and Hicher, P.-Y. (2014). Calculation of the dynamic response of a viscoelastic railway structure based on a quasi-stationary approach. Int. J. Solids Struct. 51, 22972307.

Di Mino, G., Di Liberto, M., Maggiore, C., and Noto, S. (2012). A dynamic model of ballasted rail track with bituminous sub-ballast layer. Procedia-Soc. Behav. Sci. 53, 366-378. 
Duong, N.S., Blanc, J., Hornych, P., Bouveret, B., Carroget, J., and Le feuvre, Y. (2018). Continuous strain monitoring of an instrumented pavement section. Int. J. Pavement Eng. 1-16.

Guerin, N. (1996). Approche expérimentale et numérique du comportement du ballast des voies ferrées.

Info, B. (2005). Sous Les Rails, le Bitume.

Khairallah, D., Blanc, J., Cottineau, L.M., Hornych, P., Hosseingholian, M., Ducreau, A., Pouget, S., and Voignet, P. (2017). Monitoring Of Railway Structure With Bituminous Underlayment. GEORAIL 2017 3ème Symp. Sur Géotechnique Ferrov.

Le Cam, V., Cottineau, L., Lemarchand, L., and Bourquin, F. (2008). Design of a generic smart and wireless sensors network-Benefits of emerging technologies. Struct. Health Monit. 1, 598-605.

Le Cam, V., Lemarchand, L., Martin, W., and Bonnec, N. (2010). Improving wireless sensor behavior by means of generic strategies. Struct. Health Monit. 1, 696-703.

Martin, A. (2014). Analyse numérique de la réponse dynamique de structures ferroviaires. Application à la réduction des désordres géométriques induits dans les couches de ballast des Lignes à Grande Vitesse.

Pita, A.L., Teixeira, P.F., and Robusté, F. (2004). High speed and track deterioration: the role of vertical stiffness of the track. Proc. Inst. Mech. Eng. Part F J. Rail Rapid Transit 218, 31-40.

Policicchio, F. (2007). Lineamenti di infrastrutture ferroviarie (Firenze University Press).

Quezada, J.C. (2012). Mécanismes de tassement du ballast et sa variabilité.

Robinet, A., and Cuccaroni, A. (2012). L'expérience grave-bitume de la LGV Est européenne. Rev. Générale Chemins Fer 44-50.

Rose, J.G., and Souleyrette, R.R. (2015). Asphalt Railway Trackbeds : Recent Designs, Applications and Performances, in: A.R.E. and M.-W. Association (Ed.). Proc. 2015 AREMA Annu. Conf.

Rose, J.G., Teixeira, P.F., and Ridgway, N.E. (2010). Utilization of asphalt/bituminous layers and coatings in railway trackbeds: a compendium of international applications. (American Society of Mechanical Engineers), pp. 239-255.

Rose, J.G., Teixeira, P.F., and Veit, P. (2011). International design practices, applications, and performances of asphalt/bituminous railway trackbeds. pp. 19-20.

Saussine, G. (2004). Contributiona la modélisation de granulats tridimensionnels: application au ballast. These Dr. LMGC Montp.

Suiker, A. (2002). The mechanical behavior of ballasted railway tracks (DUP Science).

Teixeira, P., López-Pita, A., Casas, C., Bachiller, A., and Robuste, F. (2006). Improvements in highspeed ballasted track design: Benefits of bituminous subballast layers. Transp. Res. Rec. J. Transp. Res. Board 43-49.

Teixeira, P., Ferreira, P., Pita, A.L., Casas, C., and Bachiller, A. (2009). The use of bituminous subballast on future high-speed lines in Spain: structural design and economical impact. Int. J. Railw. 2, 1-7. 
Teixeira, P., Lopez Pita, A., and Ferreira, P. (2010). New possibilities to reduce track costs on highspeed lines using a bituminous sub-ballast layer. Int. J. Pavement Eng. 11, 301-307.

(2014). Asphalt in Railway Tracks. E P Breukelen Pays Bas. 